\title{
THE REUSE OF RECLAIMED WATER IN URBAN AREAS: A COST-BENEFIT ANALYSIS
}

\author{
ALBERTO DEL VILLAR \\ Department of Economics and Business Management, \\ Faculty of Economics, Business and Tourism, Alcala University, Spain
}

\begin{abstract}
The high levels of quality required for urban wastewater treatment represent an opportunity to have an easily accessible resource with the high potential for use in urban activities. Traditionally, reclaimed water has been used in agriculture (irrigation), recreational and sports activities (irrigation of golf courses) and environmental uses. There are almost no cases of reusing water for urban activities, with very few exceptions, as watering parks and gardens or street cleaning. However, in an environment of increasing activities that use water and the scarcity of natural resources, reclaimed water has become an alternative for economic activities, and urban uses have acquired a higher value. The cost of generating these water resources is presented as apparently higher than the cost of a resource of natural origin. However, the benefits of using these types of resources far outweigh the cost of their availability. This facilitates the sustainable development of urban agglomerations, but does not undermine the existing natural resources. The objective of the present work is to perform a cost-benefit analysis of the reclaimed water option in the field of urban and economic activities, aside from the agricultural and recreational and sports activities that have traditionally resorted to this resource, in order to give value to this type of resource. The analysis will be illustrated with a case study and a quantitative assessment of the reuse program of reclaimed water carried out in Madrid.
\end{abstract}

Keywords: water cost, reclaimed water, resource cost, economic value of water, circular economy.

\section{INTRODUCTION}

Water has a marked economic character as a productive asset, both in the production function of economic activities, as well as functioning as an integrated element of an ecosystem that produces environmental goods. Its use is competitive and finite - that is, the appropriation of this element for a specific activity disables its use in another activity. This characteristic is what has motivated the constant search for water to the limit of natural sources in certain regions. Once this limit has been reached, there is no choice but to resort to two solutions: increase efficiency in its use and increase the supply of water with resources from other sources (desalination or reuse) or regions (transfers).

Ignoring the problems of water transfers, the regeneration of wastewater presents an additional advantage over desalination by reducing the impact generated by wastewater discharges (even with some treatment, since it does not completely eliminate the pollutant load) on the water bodies, presenting the latter, therefore, with a double value as a solution to the problems generated in the environment derived from scarcity and pollution.

In this respect, in recent years the quality requirements of the wastewater discharges mean that it is possible to use this resource in certain activities, productive and environmental, producing reclaimed water at low cost.

Traditionally, reclaimed water has been used in agriculture (irrigation) and recreational and sports activities (e.g. irrigation of golf courses). However, due to the lack of available water resources, the efficient allocation of water, even for reclaimed water, has become imperative. 
Cities are the main source of wastewater and, therefore, the major source of reclaimed water. When access to new sources of water is problematic or expensive, the option of reusing wastewater is seen as a smart alternative.

Producing reclaimed water is not cheap. The cost of the production of reclaimed water is usually high, but the most significant cost is the distribution to the users of this resource. The investment in treatment systems usually requires less financial resources than the investments in distribution networks for transporting the reclaimed water. However, the cost of not having water is much higher than the cost of producing reclaimed water.

On the basis of the foregoing assessment, the benefits of reusing wastewater are higher than the costs incurred in the production and distribution of reclaimed water, as it is demonstrated later in the paper.

\section{RECLAIMED WATER: COST OF PRODUCTION AND DISTRIBUTION}

In order to produce water services with reclaimed water, production, transport and distribution services are required. These services are not homogeneous in terms of primary product (wastewater) and location [1]. It is necessary to take into account certain factors that induce a higher or lower cost of the services depending on the projects and the use to which the treated water is destined.

Following the sequence presented by the services, the main determinant of the cost of production is the final destination of this resource. Depending on the final use of the reclaimed water, the observance of specific quality criteria is required.

The highest quality requirements are in urban uses (watering gardens or discharge of sanitary appliances), as opposed to recreational uses (watering golf courses) and environmental uses (maintenance of wetlands) that have lower quality requirements.

The second element influencing the cost of the production of reclaimed water is the quality of treated wastewater. Obviously, water that only requires additional filtration and disinfection has a lower cost than that requiring more complex processes (ultrafiltration, osmosis, electrodialysis, etc.) derived from the pollutant load or effluent quality.

The third element that contributes to production costs is the size of the project. Due to the application of economies of scale, projects with a larger volume of treated wastewater will have lower unit costs than smaller similar ones.

Finally, there is a group of costs that includes administrative standards and formal requirements (analytical operations and quality control, for example). This factor increases the cost of the distribution of reclaimed water.

The other elements that make up the system costs are their own and are of an identical nature to any production process, which requires an initial investment and the maintenance of the facilities, together with operating costs in the production.

Table 1: Range of costs for the production and distribution of reclaimed water in Spain. (Source: Villar, 2016.)

\begin{tabular}{|l|c|c|c|}
\hline & $\begin{array}{c}\text { Costs of } \\
\text { establishing } \\
€ / \mathrm{m}^{3}\end{array}$ & $\begin{array}{c}\text { Operating cost } \\
€ / \mathrm{m}^{3}\end{array}$ & $\begin{array}{c}\text { Annual } \\
\text { equivalent } \\
\text { cost } \\
€ / \mathrm{m}^{3}\end{array}$ \\
\hline Reclaimed water production & $0.20-4.50$ & $0.06-0.48$ & $0.08-0.84$ \\
\hline Reclaimed water distribution & $4.00-8.00$ & $0.15-0.40$ & $0.47-1.04$ \\
\hline \multicolumn{3}{|l|}{} & $\mathbf{0 . 5 5}-\mathbf{1 . 8 8}$ \\
\hline
\end{tabular}


The most significant differences in the production of this resource come from the quality requirements for reclaimed water uses, while the costs of transport and the distribution system are a consequence of the networks and infrastructure needed to supply reclaimed water to users.

The average cost of the production and distribution of reclaimed water in Spain is around $1.10 € / \mathrm{m}^{3}\left(0.44 € / \mathrm{m}^{3}\right.$ production cost and $0.66 € / \mathrm{m}^{3}$ transportation and distribution costs).

\section{VALUE AND COST-BENEFIT ANALYSIS}

Economic analysis enables us to evaluate the economic rationality of decisions and measures taken and contributes to the process of participation in public decision-making. Cost-benefit analysis (CBA) use economic efficiency as a guide to management decision-making. Economic efficiency is measured as the difference between the outcomes (benefits) and inputs (costs). The economic value of reclaimed water is the result of adding a set of values of use and non-use, which is known as total economic value [2]. This value results from the aggregation of the economic value and the intrinsic value of the water. The economic value is related to the productivity of water use and the induced externalities.

Total economic value refers to the value derived by people from a natural resource or an infrastructure, compared to not having it. Total economic value is a result of an aggregation of the values provided by a given ecosystem. These values can be identifying as use and non-use values.

The intrinsic values are more difficult to measure and estimate. In some cases, they can represent environmental externalities [3], which can be relatively easy to measure, while in others, as the inheritance value or the existence value, they require a more complex methodology. In order to quantify these values, methodologies based on Hedonic Prices or Contingency Valuation are commonly used.

Hedonic Prices start from considering goods and services as a set of attributes, some of which are observable and others that are not. Those attributes of goods that are observable may have an approximate value through a market price. The remaining unobservable attributes can have a value by difference.

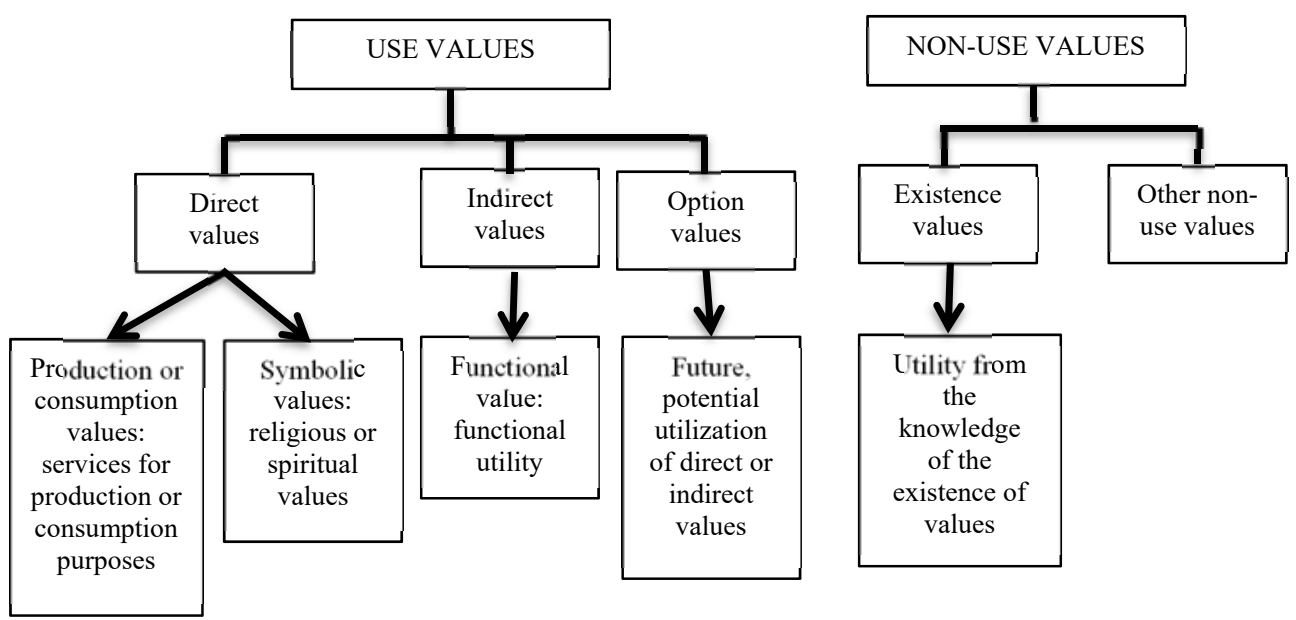

Figure 1: Use and non-use values. 
Contingent Valuation tries to establish the preferences and willingness to pay of a subject through questionnaires in which the individual reveals his preferences. This survey methodology presents the problem of bias generated in the surveys.

The Travel Cost method tries to measure the environmental value through the demand function generated by the expenses of the individuals when they visit a certain place. It looks at people's willingness to pay (measured in terms of time and travel cost expenses that people incur to visit a site). The greater the number of visits, the greater the environmental value of the good.

The method of Costs Avoided attempts to estimate the value of externalities in the environment. By measuring the value of the externalities avoided, we will obtain the environmental value of the good.

There are two ways to measure the economic value of water. It is possible to establish the economic value of reclaimed water relating to the productivity of this resource and the economic activity.

On the other hand, it is also possible to determine the value of reclaimed water use in terms of the costs of the replaced resource. The basic reason for this is the public goods character of these services, which do not have a direct market value with which we can compare. So, we use the cost of the replaced resource as a measure of the value of the reclaimed water.

There are other valuations that we can measure in economic terms beyond the value of the production of goods and services. This is the case of correcting environmental externalities like reducing the disposal of pollutants, and thereby improving the natural stream status and reducing impact.

CBA is applied to environmental policies in order to compare the social costs and benefits. These flows are compared using economic values and monetary indicators. When performing CBA, there are two types of economic values. The first category is use values (direct and indirect use), and the second is non-use values (existence values of the biodiversity and wild species, bequest for future generations, etc.).

In order to valuate costs, we begin with the most basic investment and maintenance costs. These are financial costs and do not really complicated the calculation. When we consider the economic costs, we are not only taking into account the financial cost of investment or maintenance costs, but we are also considering the opportunity costs, like the effects on economic activity and employment.

The other side of the balance, the benefits, adds further complexity. It is not a simple task to consider the financial and opportunity benefits of the activities benefited from these activities, even when some impacts of these activities can be negative (for example, the reduction of environmental flows due to reducing discharges of treated wastewater, as an example).

There are four categories of environmental benefits we can recognise due to the healthy ecological status of a water body:

1. Improving factors in goods and services supply. Reduced costs and increased welfare (availability of fresh water, for example). Unsanitary water can be detrimental to human health when this water contains some viruses, harmful germens, organic and inorganic substances (metals). Increased water quality should reduce risks over human health and also reduce water treatment cost for urban uses.

2. Cost-saving on regulating functions. Relation to an improved purification of water-related systems, cost-savings for emission abatement, costs-savings for water management, air pollutant, $\mathrm{CO}_{2}$ emissions, etc. Increasing water supply allows us to 
increase the amount of water available for households, agriculture and industry. Population growth as well as challenges from droughts and ageing infrastructure highlights the ongoing importance of water planning.

3. Improving cultural, recreational, leisure and free-time activities functions, due to environmental improvement activities. Tourism can contribute directly to the conservation of protected areas and habitat. Revenue from park entrance fees and similar sources can be allocated specifically to pay for the protection and management of environmentally sensitive areas. Tourism can significantly contribute to environmental protection, conservation and restoration of biological diversity and sustainable use of natural resources. Because of their attractiveness, pristine sites and natural areas are identified as valuable and the need to keep the attraction alive can lead to the creation of national parks and wildlife parks.

4. Environmental and ecological supporting functions. The need to improve the sustainability of the wildlife and ecosystem is a high duty of a modern society. Accounts that measure the condition of environmental assets (including ecosystems) provide society with the tools to manage natural capital, such as how and where we produce our food, and how we direct public and private investments to improve and maintain the health of our environmental assets, and they help us to adapt to the impacts of climate change.

Most of these goods and assets can be valued using market prices or other price indicators that reflect the value for their users. For example, those benefits for specific users of goods or services from water bodies as avoided costs for the treatment of drinking water. This can be estimated based on market prices. Also, some benefits that we can measure in terms of social welfare and progress are reflected in their willingness to pay for the related services, and reflect the preferences and values of the current society for those services.

But there is another category of benefits that we cannot take into account so easily intangible benefits. The non-use value refers to the value citizens attach to improvements, irrespective of their own use. These benefits are included in one of the following categories:

- Option value. Referring to the potential future use value (for example, as a source of drinking water).

- Existence value. This is important to many people and influences what they are prepared to pay for.

- Inheritance values. The value we pass to the next generation.

A key problem in the decision-making process is the determination of benefits: what benefits to consider in each case, how to value them, how long to account for them, etc. Benefits have many dimensions, and some of them have a market price since the improved environmental conditions may provide services and goods traded in markets, but there are many others which have no reflection in a market nor can be quantified via market techniques.

\section{CASE STUDY: WASTEWATER TREATMENT AND WATER REUSE IN MADRID}

In the last decades of the 20th century, the government of the region of Madrid was planning to increase the water availability of the region by the construction of two new dams in the north-east (in the Guadalajara province, which borders north-eastern Madrid). The objective was to increase the guarantee of water supplies for the next 25 years. In order to avoid water 
shortage, these risks have been increasing due to urban growth in the last years, and so it was necessary to increase the reservoir's capacity to $250-300 \mathrm{Mm}^{3}$.

The estimated total investment cost for this measure would reach a range between 70 and 100 million euros.

The current reservoir capacity of the region (essentially unchanged over the last 25 years) is around $850 \mathrm{Mm}^{3}$, so this planning scenario means increasing the damned capacity by $30 \%$. Annual water consumption in the last 20 years is around $550 \mathrm{Mm}^{3}$, with no changes, although the population has increased by $25 \%$.

With this planning scenario and a strong opposition to the new dams, in 2005 a new programme was launched. The new plan, the Madrid Dpura Plan [4], comprised several measures designed to improve wastewater treatment and water reuse.

The main objective for the widespread use of reclaimed water is to preserve the water for the supply to the population and to increase the use of reclaimed water in watering gardens, washing streets, golf course irrigation and industrial use. The Dpura Plan aims to annually produce up to $40-80 \mathrm{Mm}^{3}$ of reclaimed water, representing $8 \%-15 \%$ of the water consumed by the population of Madrid in one year. The plan seeks to replace current uses of groundwater with reclaimed water.

The Madrid Dpura Plan includes the construction of 35 new tertiary treatments plants, as well as the expansion and upgrading of three wastewater treatment plants and the extension of the reclaimed water distribution system with $1200 \mathrm{~km}$ of pipeline network, with the aim of serving 51 municipalities and around 25 golf courses and industries, which means servicing more than 2.5 million inhabitants.

The main aim of the Madrid Dpura Plan [5] is to make a positive contribution to water development schemes based on the optimisation of water resources usage, taking into account of the strategic role of groundwater resources as reserves to be included in drought management and emergency supply plans. All of these efforts are made in order to preserve the environment and landscape of the community of Madrid.

At the end of 2016 [6], 23 reclaimed water plants were ongoing and $512 \mathrm{~km}$ of the reclaimed water distribution pipe network had been completed. Reclaimed water production reached $12.41 \mathrm{Mm}^{3}$.

The initial investment earmarked for starting up the plan is around 200-300 million euros, which provides an indicator of the establishment cost of $5-8 € / \mathrm{m}^{3}$. There is no official information or data on the conservation and maintenance costs.

Operating costs of the Madrid Dpura Program have not been released and are not publicly accessible. But given that the variable consumption price applied by the Canal de Isabel II for this resource is in a range of between 0.16 and $0.35 € / \mathrm{m}^{3}$, we are given a rough idea as to what the operating costs of about 15-20 million euros per year are, excluding investments and related amortisation.

In a nutshell, in order to avoid the construction of new dams, the Madrid region has to spend around 300 million euros on a system for the treatment and reuse of wastewater.

However, given that these measures can be financially compared to the proposals of dam development, they may vary in economic terms.

Financially, the cost of the dam proposal reaches up to 100 million euros; meanwhile, the investments in water reuse measures reaches an estimated value of 300 million euros - a very simple fact that could help determine the obvious first choice for becoming more financially efficient in order to solve the problem.

But this choice of alternatives has been based on a method that is a misinterpretation of the reality. There are several economic flows that are bypassed in the process. We must carry 
out a more in-depth analysis of both alternatives in order to achieve a better understanding of the impact of these measures, not only from a financial point of view.

CBA is a tool that enables us to better regulate and assess the alternatives. We can carry out an analysis for scenarios which include an evaluation of the external costs as well the benefits.

In order to evaluate the benefits, the first step is identifying the relation between the measure and the ability of the water ecosystem to provide society with some important services such as:

- Recreation opportunities (fishing, trekking, landscapes, etc.).

- Life-support services, increased biodiversity.

- Improvements in human health.

- Reduction of risks associated with floods.

- Increased guarantee of future water availability and reduced vulnerabilities in the case of extreme droughts.

- $\quad$ Reduced risk of irreversible damages.

- Reductions in the cost of providing water services due to better water quality.

- Mitigation of impacts from climate change and security of water supplies.

All of these environmental and social benefits need to be identified, assessed and described in physical terms, in the same way as the environmental and financial costs. In this way, we can establish an impact assessment of the two alternatives.

Looking at the environmental costs, we realise that there is a big gap between the alternatives. The reclaimed water usage alternative is more environmental friendly than the dam alternative.

The dams cause irreversible environmental changes, extending their effects beyond the area of occupation of the reservoir. The major impacts come from the water reservoir, the flooding of the land to form the reservoir and the alteration of the downstream water flow. These effects have direct impacts on soils, vegetation, wildlife and lands, fishing, climate, and, especially, for local populations. But they also have negative indirect effects. Dams change the river systems (water flow, sediment transport, ecosystem, endanger aquatic life, habitat loss, biotic organisms, etc.) and the social structure of the local population (involuntary displacement; restricting access to land, water and biodiversity resources; economic activities, etc.). These negative effects have no place in the reclaimed water alternative.

Table 2: Costs and benefits levels.

\begin{tabular}{|l|l|l|}
\hline \multicolumn{1}{|c|}{ Costs (C)/benefits (B) } & Dam & $\begin{array}{l}\text { Reclaimed } \\
\text { water }\end{array}$ \\
\hline (C) Financial costs & High & Very high \\
\hline (C) Environmental costs & Very high & Very low \\
\hline (B) Recreation opportunities & Very low & High \\
\hline (B) Life-support services & Very low & Very high \\
\hline (B) Improvements in human health & Low & Very high \\
\hline (B) Flood reduction & Very high & Very low \\
\hline (B) Water availability guarantee & Low & Very high \\
\hline (B) Irreversible damages & Very low & Very high \\
\hline (B) Cost reduction of providing water & Low & Very high \\
\hline (B) Mitigation of impact of climate change & Very low & Very high \\
\hline
\end{tabular}


An approximation of the dam's environmental costs might be achieved by using a multiplication factor of 2 applicable to the financial costs.

As regards to the potential benefits of the alternatives, the balance is firmly in favour of the proposed measures of reclaimed water. Only in the issue of flood prevention does the dam project reach beyond the achievements of the reclaimed water project. In the other evaluated issues of the benefits, the dam project ranks below the reclaimed water project.

The improvements in recreational opportunities are better achieved in the case of reclaimed water than in the case of the dam. Well-preserved and sustainably managed natural areas provide an important contribution to biodiversity and rural development that attract tourism.

The dams do not exactly help to improve environmental protection, conservation and restoration of biological diversity that helps to improve life-support services increasing biodiversity. In contrast, reclaimed water reduces draw-offs from natural sources and prevents over-exploitation of these resources, allowing for the improvement of ecosystem health.

Reclaimed water helps to increase water availability guarantee and reduced vulnerabilities in the case of extreme droughts. Further, reclaimed water does not depend upon the natural hydrological cycle, unlike surface waters.

An additional benefit for the use of reclaimed water is the absence of irreversible damage to the ecosystems. There is no way of reversing a dam construction, while in the case of reclaimed water everything could return to its original state.

Increasing wastewater treatment and preserving natural resources helps to reduce the cost of providing water downstream. In the case of the Madrid region, along the central stretch of the Tajo River Basin, the improvement of the quality of the effluent that is discharged into the streams and the preservation of natural resources allows for the reduction of the costs of downstream water services. On the contrary, the dams increase the costs of downstream water services by reducing the water availability and quality.

If the area of forest affected by the reservoir created by the dam is significant, we are going to lose a major carbon sink. So, this measure does not help in the mitigation of the impact of climate change. On the other hand, reclaimed water is often accompanied by recovering chemical energy from wet organic waste (biogas formation), and it helps to reduce the carbon footprint.

Even when financial information is available, benefit information is very limited. The lack of information gives us a chance to explore other options. If we cannot make a quantitative evaluation, we can only enter a solely qualitative valuation, due to the absence of monetary valuations of environmental benefits.

It is difficult to attribute a monetary value to many types of environmental and social benefits. Even when we use economic tools, such as contingent value or travel cost methods. There is a need for pragmatic approaches in order to be able to take the benefits into account if this monetary information is incomplete or not fully available. When assessing the impacts of projects, we not only have to consider the balance between costs and benefits, but also the affordability implications.

The environmental benefit [7] is defined in practical terms as the value (welfare gain) of the goods and services provided by ecosystems. Using the contingent valuation method, we can know the willingness (or availability) to pay of individuals for environmental improvement. For the Guadalquivir River Basin, the willingness to pay has been estimated as $€ 31.78$ per household per year. There is not an estimation for the Tajo River Basin, so we can take use value in order to evaluate the benefits in the Madrid region. 
Table 3: Monetary costs and benefits. Net present value of the projects (estimation based at a $5 \%$ discount rate).

\begin{tabular}{|l|l|l|}
\hline \multicolumn{1}{|c|}{ Costs (C)/benefits (B) } & Dam & $\begin{array}{l}\text { Reclaimed } \\
\text { water }\end{array}$ \\
\hline (C) Financial costs & $100 \mathrm{M} €$ & $300 \mathrm{M} €$ \\
\hline (C) Environmental costs & $200 \mathrm{M} €$ & $0 \mathrm{M} €$ \\
\hline Total value cost & $300 \mathrm{M} €$ & $300 \mathrm{M} €$ \\
\hline (B) Benefits & $104 \mathrm{M} €$ & $1040 \mathrm{M} €$ \\
\hline & $\mathbf{- 1 9 6} \mathbf{M} €$ & $\mathbf{+ 7 4 0} \mathbf{M} €$ \\
\hline
\end{tabular}

The Madrid region has 2.6 million households, so the annual estimated benefit is around 83.5 million euros. And the actual value estimated in 20 years' time is 1040 million euros. A reclaimed water project can reach this level of benefits, while we estimate only $10 \%$ of these benefits can be attributed to the dam project (flood prevention).

The estimated present worth benefit of the reclaimed water project is around 740 million euros, while the dam project presents losses of 196 million euros.

\section{CONCLUSIONS}

In recent years there has been a steady increase in water consumption reaching almost the limits of natural resources. In this scenario, reclaimed water has become in many instances a smart alternative for meeting the demand for water in urban areas.

However, the financial costs of reclaimed water seemd to be higher than other sources of water resources. But when we introduce the additional environmental costs and other externalities this statement does not appear to be well founded.

The CBA uses economic efficiency as a guide to decision-making management. Economic efficiency is measured as the difference between the outcomes (benefits) and inputs (costs). The monetary valuation of environmental benefits falls more into the category of the so-called "intangible", basically consisting of benefits concerning improvements to the environment.

In applying these principles to water supply projects, we see how the ranking of alternatives is modified. For water projects, the economic effect can involve beneficial or adverse effects. In order to evaluate a water project, it is not only the financial effects that must be considered, but also the environmental impacts and others.

A case study looking at the application of these instruments to the region of Madrid gives us the chance to show how environmental valuation can change the ranking of project alternatives.

Initially, the dam project seems to be the most efficient choice, from a financial point of view. However, considering the environmental issues, a reclaimed water project seems to be the best option.

\section{REFERENCES}

[1] Villar, A., Reuse of reclaimed water: an approach to production costs and valuation. Agua y Territorio, 8, pp. 70-79, 2016.

[2] De la Cámara, G., Guía para decisores Análisis económico de externalidades ambientales, Comisión Económica para América Latina y el Caribe (CEPAL): Santiago de Chile, 2008. 
[3] Alfanca, O., García, J. \& Varela, H., Economic valuation of a created wetland fed with treated wastewater located in a peri-urban park in Catalonia, Spain. Water Science and Technology, 63(5), pp. 891-898, 2011.

[4] Comunidad de Madrid, Dirección General de Medio Ambiente, Madrid. http://www.madrid.org/cs/Satellite?c=CM InfPractica FA\&cid=1114178464601\&lan guage $=$ es\&pagename $=$ ComunidadMadrid $\% 2$ FEstructura $\& p v=1142670256087$. Accessed on: 3 Jan. 2018.

[5] Martín López, A., Plan de reutilización del agua en la Comunidad de Madrid. Presented at Zaragoza Expo 2008 Conference "Agua y servicios de abastecimiento $y$ saneamiento", Zaragoza, Spain, 2008.

[6] Canal de Isabel II, Madrid. http://www.canaldeisabelsegunda.es/en/conocenos/cifras/ Canal/index.html. Accessed on: 19 Sep. 2017.

[7] Martín, J., Berbel, J. \& Brouwer, R., Valoración económica de los beneficios ambientales de no mercado derivados de la mejora de la calidad del agua: una estimación en aplicación de la Directiva Marco del Agua al Guadalquivir. Economía Agraria y Recursos Naturales, 9(1), pp. 65-89, 2009. 